\title{
PHD Defence: "Luck and Liberty: The Political Economy of Life Chances" By Scott Timcke
}

\author{
Sibo Chen \\ School of Communication \\ Simon Fraser University \\ Our dear colleague, Scott Timcke, successfully defended his PHD dissertation on February 19, 2015. \\ Here is the abstract of his dissertation "Luck and Liberty: The Political Economy of Life Chances":
}

\begin{abstract}
In the wake of growing unrest about economic disparities between the "one per cent" and other classes in western societies, I argue that an assessment of life chances in contemporary capitalist liberal democracies has assumed a renewed urgency. There are many other factors outside of a person's socioeconomic position that can influence life chances, such as race, gender, or ethnicity, in addition to intersections with place of birth, education and income, so that the lived experience of class often has a distinctively multidimensional character. Still, the focus in this dissertation is directed at higher levels of abstraction dealing with the political economy of life chances as a feature of life in western capitalist liberal democracies-societies often promoted as the freest and the most equitable in the world.

To address these issues I develop a conceptual test to demonstrate how unfair contemporary capitalist societies happen to be. I do this because too often debates about unfairness and inequality become squabbles about the accuracy of data and the suitability of econometric models but miss the point about ethics and exploitation; all of which distracts from reform. Developing this test has necessitated a movement through discussions of luck egalitarianism in the moral philosophies of liberalism and Marxism to demonstrate that much of what a person seeks to claim as their own is radically contingent. Irrespective of whether economic inequalities are caused by the genetic lottery of natural talents, the social lottery of opportunities to develop talents, or the market lottery where a person's attributes become talents because they just happen to be in demand, are inherently unjust. Further, examining the role of market economies and institutional design in allocating life chances and rewards cannot be separated from a conception of what human flourishing happens to be and how it can likely be achieved. In this respect, I offer a small contribution to an analysis of inequality by developing a principle of justice, which I call 'the quality of prospects.'

To support the aforementioned principle, I distinguish between two kinds of luck: hard luck and institutional luck. I take hard luck to be items that are contingent and accidental as determined via ontological naturalism and qualified modal realism. By institutional luck I mean entrenched structured allocations of life chances as determined by social forces. While there is a tendency to confuse hard luck with institutional luck, I argue that what often appears simply as hard luck has an institutional anchorage that to some degree can be amenable to human intervention. Thus any adequate discussion of luck necessarily commits one to consider politics.

If one assumes that the amelioration of social inequality requires a major redistribution of life chances, my argument in this dissertation is that such redistribution ought to be based on a subtle appreciation of how luck occurs. I endorse the view that social equality is a necessary foundational component to an adequate theory of justice. This is because undue inequality exacerbates a general condition of alienation thereby hindering genuine human flourishing.
\end{abstract}

Keywords: social inequality; liberalism; Marxism; luck; redistributive justice 